\title{
Corroboration of the J-value model for life- expectancy growth in industrialized countries
}

\author{
Philip Thomas*
}

\author{
Safety Systems Research Centre ${ }^{* *}$ \\ Queen's School of Engineering, University of Bristol, \\ Queen's Building, University Walk, Bristol BS8 1TR
}

\begin{abstract}
After including an allowance for the gap between male and female life expectancies at birth diminishing over the past 50 years in industrialized countries, the J-value model incorporating "male catch-up" has been validated against actual UK data on life expectancy. A close correspondence has also been found between forecasts for life expectancy at birth in 35 countries made by the J-value model and those produced in a recent study that applied Bayesian model averaging to 21 demographic projection models.
\end{abstract}

Keywords: GDP per head, J-value, life expectancy projections, male catch-up

\section{Introduction}

Based on the life quality index, ${ }^{\mathbf{1 , 2}}$ the $\mathrm{J}$-value is an objective method for determining when lifeextending measures are sensible, as has been described. ${ }^{3-6}$ It has been possible to apply the J-value principles to derive a model to explain the variation in life expectancy amongst the

* E-mail: philip.thomas@bristol.ac.uk

** Research website: www.jvalue.co.uk

1 Nathwani, J.S. and Lind, N.C., Affordable Safety by Choice: the Life Quality Method. Waterloo, Ontario: Institute for Risk Research, University of Waterloo (1997).

2 Nathwani, J.S., Pandey, M.D. and Lind, N.C., Engineering Decisions for Life Quality: How Safe is Safe Enough? London: Springer (2009).

3 Thomas, P., Does health spending need to outpace GDP per head? Nanotechnology Perceptions 13 (2017) 17-30.

4 Thomas, P.J., Stupples, D.W. and Alghaffar, M.A., The extent of regulatory consensus on health and safety expenditure. Part 1: Development of the J-value technique and evaluation of regulators' recommendations. Trans IChemE, Part B, Process Safety and Environmental Protection 84(B5) (2006) 329-336.

5 Thomas, P.J., Stupples, D.W. and Alghaffar, M.A., The extent of regulatory consensus on health and safety expenditure. Part 2: Applying the J-value technique to case studies across industries. Trans IChemE, Part B, Process Safety and Environmental Protection 84(B5) (2006) 337-343.

6 Thomas, P.J., Jones, R.D. and Kearns, J.O., The trade-offs embodied in J-value analysis. Process Safety and Environmental Protection 88 (2010) 147-167. 
nations of the world. ${ }^{7,3}$ The high explanatory power of that model in this task provides validation for the J-value method for assessing safety and health protection measures. Inter alia, it was shown in Thomas and Waddington ${ }^{7}$ that the differences in national life expectancy at birth could be well explained in terms of differences in gross domestic product (GDP) per head using a value for risk-aversion that was the same for all countries. Hence, it might be expected that the J-value model for life expectancy would apply within the same nation to trace how the life expectancy at birth increases as national GDP per head grows. It is this proposition that will be tested in this paper, which is a supplement to the preceding one. ${ }^{3}$

J-value model outputs will be compared first against actual life expectancy data for the $\mathrm{UK},{ }^{8}$ using data on economic growth from the World Bank. ${ }^{9}$ Then the J-value model forecasts for life expectancy in 2030 will be set against projections for 35 industrialized countries made recently by Kontis et al. ${ }^{10,11}$

\section{Comparison between the J-value and UK data on life expectancy at birth}

\subsection{The J-value model for life expectancy at birth}

In the J-value life expectancy model, ${ }^{3}$ the basic equation linking combined genders life expectancy at birth, $X(0)$, at some general, future time to its corresponding starting value, $X_{\mathrm{A}}(0)$, may be written:

$$
X(0)=X_{\mathrm{A}}(0)\left(\frac{G}{G_{\mathrm{A}}}\right)^{1-\varepsilon_{\mathrm{P}}},
$$

where $G_{\mathrm{A}}$ is the starting GDP per head, $G$ is the GDP per head at the future time, and $\varepsilon_{\mathrm{p}}$ is the risk-aversion associated with the Preston curve of life expectancy at birth versus GDP per head across all the world's nations. ${ }^{7,}{ }^{12}$ Assuming for simplicity that GDP per head increases over a period of $n$ years with a uniform growth rate, $g\left(\right.$ year $\left.^{-1}\right)$, the later GDP per head will be given by:

$$
G=G_{\mathrm{A}}(1+g)^{n} .
$$

Substituting from equation (2) into equation (1) then produces:

$$
X(0)=X_{\mathrm{A}}(0)(1+g)^{n\left(1-\varepsilon_{\mathrm{p}}\right)} .
$$

The appropriate risk-aversion for use with the Preston curve is given as $\varepsilon_{\mathrm{p}}=0.91{ }^{7}$

The J-value model predicts about $80 \%$ of the variation in life expectancy at birth with GDP per head across nations, viz. the square of the correlation coefficient, $R^{2}$, is found to be 0.78 for

7 Thomas, P.J. and Waddington, I., Validating the J-value safety assessment tool against pan-national data. Process Safety and Environmental Protection (submitted in 2017).

8 National Life Tables, Great Britain, 1980-2 to 2013-5, released 29 September 2016. Office of National Statistics (ONS) (2016) [accessed at: https://www.ons.gov.uk/peoplepopulationandcommunity/ birthsdeathsandmarriages/lifeexpectancies/datasets/nationallifetablesgreatbritainreferencetables]

9 World Development Indicators: GDP per capita growth (annual \%), updated 1 February 2017. World Bank (2017) [accessed at: http://data.worldbank.org/indicator/NY.GDP.PCAP.KD.ZG]

${ }^{10}$ Kontis, V., Bennett, J.E., Mathers, C.D., Li, G., Foreman, K. and Ezzati, M., Future life expectancy in 35 industrialised countries: projections with a Bayesian model ensemble. The Lancet 389 (2017) 1323-1335.

${ }^{11}$ Supplement to ref. 10.

${ }^{12}$ Preston, S.H., The changing relation between mortality and level of economic development. Population Studies 29 (1975) 231-248. 
162 nations. ${ }^{7}$ However, the application of the J-value model within a given country A has the advantage that the starting pair, $X_{\mathrm{A}}(0), G_{\mathrm{A}}$, will be specific to that nation. This boundary condition provides an anchoring point at zero time that allows the model potentially to have greater predictive power: the estimation of later life expectancy from projected GDP per head can be regarded as a perturbation from a known starting point. For example, despite the fact that the USA has a GDP per head roughly a third higher than the UK's, the J-value model will be seen to forecast a higher life expectancy in 2030 for the UK as a result of British life expectancy at birth being about $2 \frac{1}{2} \%$ higher in 2010 .

\subsection{Combined genders life expectancy}

Let the life expectancy at birth (exact age $=0$ ) be $X_{\mathrm{m}}(0)$ for males and $X_{\mathrm{f}}(0)$ for females. The fraction of boys among all births is given by Weisskopf ${ }^{\mathbf{1 3}}$ as $f_{\mathrm{m}}=0.512$, allowing the combined genders life expectancy at birth, $X(0)$, to be calculated as:

$$
X(0)=f_{\mathrm{m}} X_{\mathrm{m}}(0)+\left(1-f_{\mathrm{m}}\right) X_{\mathrm{f}}(0)
$$

A parallel equation will obviously hold for the combined genders life expectancy at birth, $X_{\mathrm{A}}(0)$ at an earlier time:

$$
X_{\mathrm{A}}(0)=f_{\mathrm{m}} X_{\mathrm{mA}}(0)+\left(1-f_{\mathrm{m}}\right) X_{\mathrm{fA}}(0) .
$$

Table 1 shows the male, female and resultant combined genders life expectancy at birth in the United Kingdom in 1985 and 2005, taken from the life tables for 1984-1986 and 2004-2006 provided by the Office for National Statistics (ONS). ${ }^{8}$ The 20-year period 1985 to 2005 was chosen for the test as it is long enough to allow sizeable changes in life expectancy, but avoids both the significant economic recession of 1980-1981 and the prolonged and deep recession experienced in 2008-2009, although it includes the 1991 UK recession. The average growth in GDP per head over the period may found from World Bank data ${ }^{9}$ to be $2.45 \%$ per annum.

Table 1. At-birth life expectancies in the United Kingdom in 1985 and $2005 .^{8}$

\begin{tabular}{ccccccc}
\hline & \multicolumn{5}{c}{ Life expectancy at birth / years } \\
\cline { 2 - 7 } Country & \multicolumn{5}{c}{1985} & \multicolumn{3}{c}{2005} \\
\cline { 2 - 7 } & Male, & Female, & Combined, & Male, & Female, & Combined, \\
& $X_{\mathrm{Am}}(0)$ & $X_{\mathrm{Af}}(0)$ & $X_{\mathrm{A}}(0)$ & $X_{\mathrm{m}}(0)$ & $X_{\mathrm{f}}(0)$ & $X(0)$ \\
\hline United Kingdom & 71.76 & 77.56 & 74.59 & 76.9 & 81.25 & 79.02 \\
\hline
\end{tabular}

Assuming the same growth rate for life expectancy for the two sexes, equation (3) may be applied either to the starting combined genders life expectancy at birth or else, in a decomposition, to the starting male and female life expectancies at birth. The result of the second option may then be combined using equation (4) to find the life expectancy at birth averaged over the two genders. This equivalence between the two approaches may be shown by substituting from equations (4) and (5) into equation (3):

\footnotetext{
${ }^{13}$ Weisskopf, M., Is a pregnant woman's chance of giving birth to a boy 50 percent? Scientific American 316 (January 2017) [https://www.scientificamerican.com/article/is-a-pregnant-womans-chan/]
} 


$$
\begin{aligned}
X(0) & =f_{\mathrm{m}} X_{\mathrm{m}}(0)+\left(1-f_{\mathrm{m}}\right) X_{\mathrm{f}}(0) \\
& =\left(f_{\mathrm{m}} X_{\mathrm{Am}}(0)+\left(1-f_{\mathrm{m}}\right) X_{\mathrm{Af}}(0)\right)(1+g)^{n\left(1-\varepsilon_{\mathrm{P}}\right)} \\
& =f_{\mathrm{m}} X_{\mathrm{Am}}(0)(1+g)^{n\left(1-\varepsilon_{\mathrm{P}}\right)}+\left(1-f_{\mathrm{m}}\right) X_{\mathrm{Af}}(0)(1+g)^{n\left(1-\varepsilon_{\mathrm{p}}\right)} .
\end{aligned}
$$

Equating coefficients of $f_{\mathrm{m}}$ and $1-f_{\mathrm{m}}$ in line 3 and in the right-hand side of line 1 of equation (6) shows that the male, $X_{\mathrm{m}}(0)$, and female, $X_{\mathrm{f}}(0)$, life expectancies at birth will depend on their counterparts at an earlier date:

and

$$
X_{\mathrm{m}}(0)=X_{\mathrm{Am}}(0)(1+g)^{n\left(1-\varepsilon_{\mathrm{P}}\right)}
$$

$$
X_{\mathrm{f}}(0)=X_{\mathrm{Af}}(0)(1+g)^{n\left(1-\varepsilon_{\mathrm{P}}\right)} .
$$

\begin{tabular}{|c|c|c|c|c|c|c|}
\hline \multirow{3}{*}{ Country } & \multicolumn{6}{|c|}{ Life expectancy at birth / years } \\
\hline & \multicolumn{3}{|c|}{1985} & \multicolumn{3}{|c|}{2005} \\
\hline & $\begin{array}{l}\text { Male, } \\
X_{\mathrm{Am}}(0)\end{array}$ & $\begin{array}{c}\text { Female, } \\
X_{\mathrm{Af}}(0)\end{array}$ & $\begin{array}{c}\text { Combined, } \\
X_{\mathrm{A}}(0)\end{array}$ & $\begin{array}{l}\text { Male, } \\
X_{\mathrm{m}}(0)\end{array}$ & $\begin{array}{c}\text { Female, } \\
X_{\mathrm{f}}(0)\end{array}$ & $\begin{array}{c}\text { Combined, } \\
X(0)\end{array}$ \\
\hline $\begin{array}{l}\text { UK Actual } \\
\text { UK J-value model } \\
\text { Difference }\end{array}$ & 71.76 & 77.56 & 74.59 & $\begin{array}{c}76.90 \\
74.95 \\
1.95\end{array}$ & $\begin{array}{c}81.25 \\
81.01 \\
0.24\end{array}$ & $\begin{array}{c}79.02 \\
77.91 \\
1.11\end{array}$ \\
\hline
\end{tabular}

Applying the J-value model to the 1985 values for life expectancy at birth produces the results for 2005 shown in Table 2.

Table 2. Comparison of basic J-value model predictions with at-birth life expectancies in the UK in 2005.

The basic J-value model predicts a female life expectancy at birth in 2005 that is within 3 months of the actual figure. But, the forecast for male life expectancy at birth is nearly two years low. Hence, the combined life expectancy at birth in 2005 is estimated as 77.91 years, which is 1.11 years less than the actual value of 79.02 years.

It is clear that the basic J-value model does not account for what may be termed, "male catch-up". For dividing equation (7) by equation (8) gives:

$$
\frac{X_{\mathrm{m}}(0)}{X_{\mathrm{f}}(0)}=\frac{X_{\mathrm{Am}}(0)}{X_{\mathrm{Af}}(0)},
$$

which is only approximately true. In reality, male life expectancy at birth in the UK lagged 5.8 years behind that of females in 1985 , but the gap had closed to 4.4 years in 2005 , with the ratio $r_{X}$ of male to female life expectancy at birth increasing from 0.925 to 0.946 over that 20 -year period.

The next section will outline a simple model of the phenomenon of "male catch-up" that can be incorporated into the J-value approach without difficulty.

\subsection{Male catch-up}

The reasons for women living longer, on average, than men in industrialized countries have been discussed. ${ }^{14}$ Chromosomal redundancy and biological roles are identified as underlying

${ }^{14}$ Desjardins, B., Why is life expectancy longer for women than it is for men? Scientific American 316 (February 2017) [https://www.scientificamerican.com/article/why-is-life-expectancy-lo/] 
causes for women's higher life expectancy, but Desjardins concludes that “women's biological advantage now appears relatively minor in the total mortality differences between the sexes". ${ }^{14}$

Figure 1 shows the recorded behaviour of the ratio $r_{X}=X_{\mathrm{m}}(0) / X_{\mathrm{f}}(0)$ of male to female life expectancy at birth in the UK over a period from the late 1960s to 2015. The 33 contiguous data points come from ONS, ${ }^{8}$ while the figure of 0.917 for 1967 comes from the Longevity Science Advisory Panel (LSAP), ${ }^{15}$ which states:

The difference between female and male life expectancy at birth peaked at 6.25 years in 1965-69 (8.3\% of the female life expectancy at birth). In each subsequent five year period the difference has fallen in absolute and percentage terms.

The data were matched by model consisting of a critically damped 2 nd order linear, dynamic system subjected to a step input of $r_{X \text { max }}-r_{X}\left(t_{0}\right)$ at time $t_{0}$. A 2 nd order linear system is the simplest that is able to exhibit reasonably complex modes of behaviour, a fact well known to control engineers, who often employ a 2nd order system in their models to represent a plant known to be much more complex.

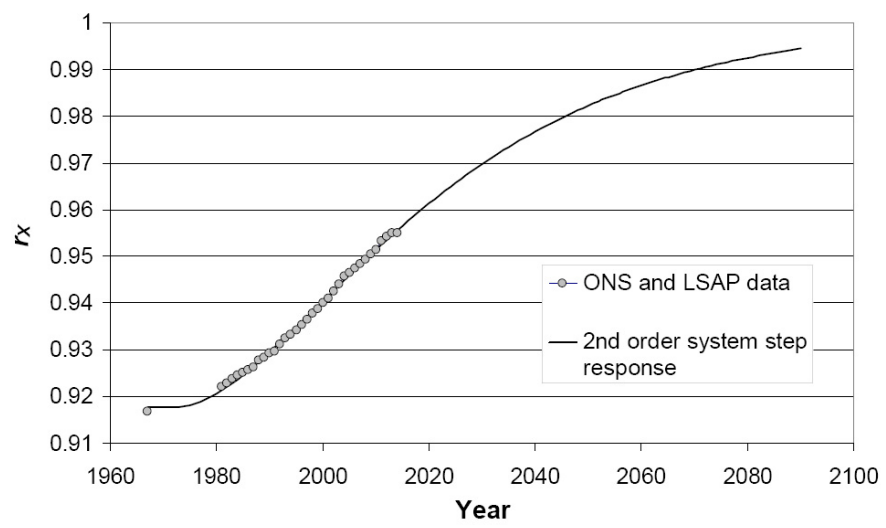

Figure 1. Variation in time of the ratio of male to female life expectancy at birth in the UK. Data from ONS and LSAP; matching 2nd order system step response.

Using $\tau$ to represent the interval since the step has been applied:

$$
\tau=t-t_{0}
$$

the value of the ratio $r_{X}$ is given by:

$$
r_{X}\left(t_{0}+\tau\right)= \begin{cases}r_{X}\left(t_{0}\right) & \text { for } \tau \leq 0 \\ r_{X}\left(t_{0}\right)+\left(r_{X \text { max }}-r_{X}\left(t_{0}\right)\right)\left(1-e^{-\frac{2 \pi}{T_{\mathrm{n}}} \tau}\left(1+\frac{2 \pi}{T_{\mathrm{n}}} \tau\right)\right) & \text { for } \tau>0\end{cases}
$$

where $T_{\mathrm{n}}$ is the system's natural period (in years) (see, for example, Singh et al. ${ }^{\mathbf{1 6}}$ ).

The sum of the squared differences between the step response model and the 34 ONS and LSAP data points was minimized through the optimal selection of the following parameters

${ }^{15}$ Past and Future Variations by Gender in England \& Wales (LSAP paper 2). Longevity Science Advisory Panel (2012) [accessed March 2017 at: http://www.longevitypanel.co.uk/files/life-expectancy-by-gender.pdf]

${ }^{16}$ Singh, M.G., Elloy, J.-P., Mezencev, R. and Munro, N., Applied Industrial Control. Oxford: Pergamon Press (1980). 
featuring in equation (11):

- the time $t_{0}$ at which the step is assumed to be applied to the 2 nd order system;

- the natural period of the system $T_{\mathrm{n}}$;

- the starting value of the life expectancy ratio $r_{X}\left(t_{0}\right)$;

- the asymptotic value of the life expectancy ratio $r_{X \max }$, subject to the constraint $r_{X \max } \leq 1$.

The optimal values were found and given in Table 3.

Table 3. Parameters of equation (11) producing the optimal match to ONS and LSAP data for the life expectancy ratio, $r_{X}$, for the UK.

\begin{tabular}{cccc}
\hline $\begin{array}{c}\text { Date, } t_{0} \text {, of } \\
\text { application of step } \\
\text { /years }\end{array}$ & $\begin{array}{c}\text { Natural period of } \\
\text { the system, } T_{\mathrm{n}} \\
\text { /years }\end{array}$ & $\begin{array}{c}\text { Starting value of the life } \\
\text { expectancy ratio, } r_{X}\left(t_{0}\right)\end{array}$ & $\begin{array}{c}\text { Asymptotic value of the } \\
\text { life expectancy ratio, } r_{X \max }\end{array}$ \\
\hline 1972.2 & 169.1 & 0.9178 & 1.0 \\
\hline
\end{tabular}

The optimal value, $t_{0}=1972.2$, provides a reasonable match to the starting date for the start of the male catch-up process in the UK, identified by LSAP as 1965-69. Meanwhile the corresponding starting ratio, $r_{X}\left(t_{0}\right)=0.9178$, is close to the recorded value of 0.9167 . The duration found for the natural period of the system, $T_{\mathrm{n}}=169.1$ years, suggests a very gradual catch-up process. Meanwhile the optimal match occurred at a asymptotic life expectancy ratio of $r_{X \max }=1$. This suggests that male life expectancy at birth will eventually equal that of females, a finding broadly in line with Desjardins' conclusion. ${ }^{14}$ Figure 1 shows that these values give a good match to the ONS and LSAP data points.

The J-value model incorporating male catch-up thus consists of a prediction for female life expectancy at birth from equation (8), with the male life expectancy at birth then given by

$$
X_{\mathrm{m}}(0)=r_{X}(t) X_{\mathrm{f}}(0) \text {. }
$$

The combined genders life expectancy at birth is given by equation (4), which allows the following expression to be written for the combined genders life expectancy at birth at some later date:

$$
X(0)=X_{\mathrm{Af}}(0)\left(1-\left(1-r_{X}(t)\right) f_{\mathrm{m}}\right)(1+g)^{n\left(1-\varepsilon_{\mathrm{p}}\right)},
$$

where $r_{X}(t)$ is given by equation (11).

Applying the simple model of equations (11) and (13) to predict UK life expectancy at birth in 2005 from corresponding figures in 1985 gives the results shown in Table 4. The model error is now reduced to about 3 months for life expectancy at birth for each of male, female and combined genders.

Table 4. The predictions of the J-value model incorporating male catch-up compared against ONS

\begin{tabular}{|c|c|c|c|c|c|c|}
\hline \multirow{3}{*}{ Country } & \multicolumn{6}{|c|}{ Life expectancy at birth / years } \\
\hline & \multicolumn{3}{|c|}{1985} & \multicolumn{3}{|c|}{2005} \\
\hline & $\begin{array}{c}\text { Male, } \\
X_{\text {Am }}(0)\end{array}$ & $\begin{array}{c}\text { Female, } \\
X_{\mathrm{Af}}(0)\end{array}$ & $\begin{array}{c}\text { Combined, } \\
X_{\mathrm{A}}(0)\end{array}$ & $\begin{array}{l}\text { Male, } \\
X_{\mathrm{m}}(0)\end{array}$ & $\begin{array}{c}\text { Female, } \\
X_{\mathrm{f}}(0)\end{array}$ & $\begin{array}{c}\text { Combined } \\
X(0)\end{array}$ \\
\hline UK Actual & 7176 & 7756 & 7450 & 76.90 & 81.25 & 79.02 \\
\hline UK J-value model incorporating male catch-up & 11.10 & 11.50 & 14.59 & 76.64 & 81.01 & 78.77 \\
\hline Difference & & & & 0.26 & 0.24 & 0.25 \\
\hline
\end{tabular}
figures for at-birth life expectancy in the UK in 2005.

Nanotechnology Perceptions Vol. 13 (2017) 


\section{Life expectancy projections to 2030 for 35 industrialized countries}

\subsection{The Bayesian model averaging method of Kontis et al.}

Kontis et al. attempted recently ${ }^{\mathbf{1 0}}, 11$ to forecast life expectancies in 2030 across 35 industrialized countries by applying Bayesian model averaging to the results of 21 forecasting models that used demographic data. Table 5 shows the 35 industrialized countries and the Kontis forecasts for life expectancy at birth in 2030, projected from comparable figures for 2010. The life expectancies at birth in the columns marked "Combined", viz. $X_{\mathrm{A}}(0), X(0)$ have been calculated by assuming that the fraction of boys among all births in all 35 nations is $f_{\mathrm{m}}=0.512$, the figure given by Weisskopf. ${ }^{13}$

Table 5. Projected life expectancies in 2030 in 35 industrialized countries from Kontis et al., ${ }^{\mathbf{1 0}, 11}$ using male fraction from Weisskopf ${ }^{13}$ to calculate the combined genders figure.

\begin{tabular}{|c|c|c|c|c|c|c|}
\hline \multirow{3}{*}{ Country name } & \multicolumn{6}{|c|}{ Life expectancy at birth / years } \\
\hline & \multicolumn{3}{|c|}{2010} & \multicolumn{3}{|c|}{2030} \\
\hline & $\begin{array}{c}\text { Male, } \\
X_{\mathrm{Am}}(0) \\
\end{array}$ & $\begin{array}{c}\text { Female, } \\
X_{\mathrm{Af}}(0) \\
\end{array}$ & $\begin{array}{c}\text { Combined, } \\
X_{\mathrm{A}}(0) \\
\end{array}$ & $\begin{array}{l}\text { Male, } \\
X_{\mathrm{m}}(0) \\
\end{array}$ & $\begin{array}{c}\text { Female, } \\
X_{\mathrm{f}}(0)\end{array}$ & $\begin{array}{c}\text { Combined, } \\
X(0)\end{array}$ \\
\hline Australia & 80.10 & 84.53 & 82.26 & 84.00 & 87.57 & 85.74 \\
\hline Austria & 77.73 & 83.21 & 80.40 & 81.40 & 86.22 & 83.75 \\
\hline Belgium & 77.35 & 82.76 & 79.99 & 80.88 & 85.64 & 83.20 \\
\hline Bulgaria & 70.21 & 77.33 & 73.68 & 74.07 & 78.87 & 76.41 \\
\hline Canada & 79.41 & 83.94 & 81.62 & 83.89 & 87.09 & 85.45 \\
\hline Chile & 76.74 & 82.95 & 79.77 & 80.74 & 86.89 & 83.74 \\
\hline Croatia & 73.10 & 79.80 & 76.37 & 77.80 & 83.19 & 80.43 \\
\hline Czech Republic & 74.36 & 80.63 & 77.42 & 79.51 & 84.42 & 81.91 \\
\hline Denmark & 77.22 & 81.33 & 79.23 & 82.53 & 84.95 & 83.71 \\
\hline Finland & 76.72 & 83.30 & 79.93 & 81.05 & 86.43 & 83.68 \\
\hline France & 77.93 & 84.86 & 81.31 & 81.74 & 88.55 & 85.06 \\
\hline Germany & 77.91 & 82.81 & 80.30 & 81.96 & 85.86 & 83.86 \\
\hline Greece & 77.89 & 82.63 & 80.20 & 80.59 & 84.82 & 82.65 \\
\hline Hungary & 70.65 & 78.42 & 74.44 & 78.18 & 81.74 & 79.92 \\
\hline Ireland & 77.96 & 82.59 & 80.22 & 83.22 & 86.15 & 84.65 \\
\hline Italy & 78.94 & 84.18 & 81.50 & 82.82 & 87.28 & 85.00 \\
\hline Japan & 79.44 & 86.66 & 82.96 & 82.75 & 88.41 & 85.51 \\
\hline Macedonia, FYR & 72.29 & 76.47 & 74.33 & 74.65 & 77.83 & 76.20 \\
\hline Mexico & 73.15 & 78.91 & 75.96 & 76.15 & 82.96 & 79.47 \\
\hline Netherlands & 78.91 & 82.85 & 80.83 & 83.69 & 85.39 & 84.52 \\
\hline New Zealand & 79.01 & 82.80 & 80.86 & 83.59 & 85.96 & 84.75 \\
\hline Norway & 78.69 & 83.08 & 80.83 & 83.16 & 85.55 & 84.33 \\
\hline Poland & 71.86 & 80.40 & 76.03 & 77.21 & 84.01 & 80.53 \\
\hline Portugal & 76.71 & 83.14 & 79.85 & 81.68 & 87.52 & 84.53 \\
\hline Romania & 70.12 & 77.46 & 73.70 & 74.21 & 81.24 & 77.64 \\
\hline Serbia & 70.25 & 75.71 & 72.91 & 73.37 & 78.27 & 75.76 \\
\hline Singapore & 75.87 & 81.54 & 78.64 & 79.57 & 84.81 & 82.13 \\
\hline Slovak Republic & 71.62 & 79.25 & 75.34 & 76.98 & 82.92 & 79.88 \\
\hline Slovenia & 75.88 & 82.68 & 79.20 & 82.26 & 87.42 & 84.78 \\
\hline South Korea & 77.11 & 84.23 & 80.58 & 84.07 & 90.82 & 87.36 \\
\hline Spain & 78.66 & 84.83 & 81.67 & 83.47 & 88.07 & 85.71 \\
\hline Sweden & 79.55 & 83.49 & 81.47 & 82.52 & 85.98 & 84.21 \\
\hline Switzerland & 80.01 & 84.59 & 82.25 & 83.95 & 87.70 & 85.78 \\
\hline United Kingdom & 78.34 & 82.32 & 80.28 & 82.47 & 85.25 & 83.83 \\
\hline United States & 76.52 & 81.24 & 78.82 & 79.51 & 83.32 & 81.37 \\
\hline Average & 76.23 & 81.91 & 79.01 & 80.56 & 85.12 & 82.78 \\
\hline
\end{tabular}


The 21 mathematical models used by Kontis et al. incorporated data on population and deaths supplied predominantly by the World Health Organization. ${ }^{17}$ Kontis et al. stated that they had employed all the demographic data available to them at that time in producing their projections for 2030. The population data began in 1960 in 24 of the 35 countries and between 1961 and 1985 for the remaining cases. The end date for each time series varied between 2010 and 2014, with an average of 2012.6. The resulting forecasts were then combined probabilistically using Bayesian model averaging.

The actual combined genders at-birth life expectancy in 2010 averaged across the 35 nations and using the Weisskopf male birth fraction is 79.01 years, while the corresponding figure for 2030 projected by the Bayesian model averaging method is 3.78 years higher, at 82.78 years.

For a test projection period of 22 years using known data, Kontis et al. reported that the best single model (out of the 21) had an absolute bias compared with actual data and averaged across the 35 countries of 1 year for females and 1.39 years for males. Bayesian model averaging based on 21 models reduced those figures for average absolute bias to 0.68 years and 1.09 years, respectively. Given that the change in life expectancy to be predicted over the 20 -year period is of the order of only 4 years, it may be concluded that the exact change is difficult to predict. Thus, it may be difficult to claim high accuracy for any of the individual models or even for the Bayesian model averaging composite method.

3.2 Life expectancy projections for 35 industrialized countries using the J-value without male catch-up

Growth rates for GDP per head, $g_{i}, i=1,2, \ldots, 35$, were considered with the end date specified as 2013 so as to match the average end date (2012.6) for the demographic data employed in the Kontis projections. The World Bank time series for the growth of GDP per head started in 1961, allowing the long-term growth rate to be calculated as the average of 53 values to 2013 for 22 out of the 35 countries (c.f. 54 years' demographic data for the Kontis approach for 24 countries), with shorter runs of data available for the remaining 13 countries: Bulgaria (33 years), Croatia (18), Czech Republic (23), Germany (43), Hungary (22), Ireland (43), FYR Macedonia (23), New Zealand (36), Poland (23), Romania (23) Serbia (18), Slovak Republic (21) and Slovenia (18). The growth rate, $g_{i}, i=1,2, \ldots, 35$, for GDP per head used in equation (13) for each nation was taken as the arithmetic average over the number of data points available between 1961 and 2013. The resulting average long-term growth rate of GDP per head across the 35 nations was $2.55 \%$ p.a.

Figure 2 shows a comparison of the J-value calculated life expectancy at birth in 2030 for combined genders with the Kontis et al. results on a country by country basis. It is clear that there is good agreement overall between the Bayesian model averaging and J-value models. The average long-term growth rate of $2.55 \%$ (measured over a period of 50 years for about two thirds of the countries) leads to an overall, combined gender life expectancy in 2030 predicted by the J-value model to be 82.67 years, a little over a month less than the overall figure of 82.78 predicted by Kontis et al.

\footnotetext{
${ }^{17}$ World Report on Ageing and Health. Geneva: World Health Organization (2015) [accessed at: http:// www.who.int/ageing/events/world-report-2015-launch/en/]
} 


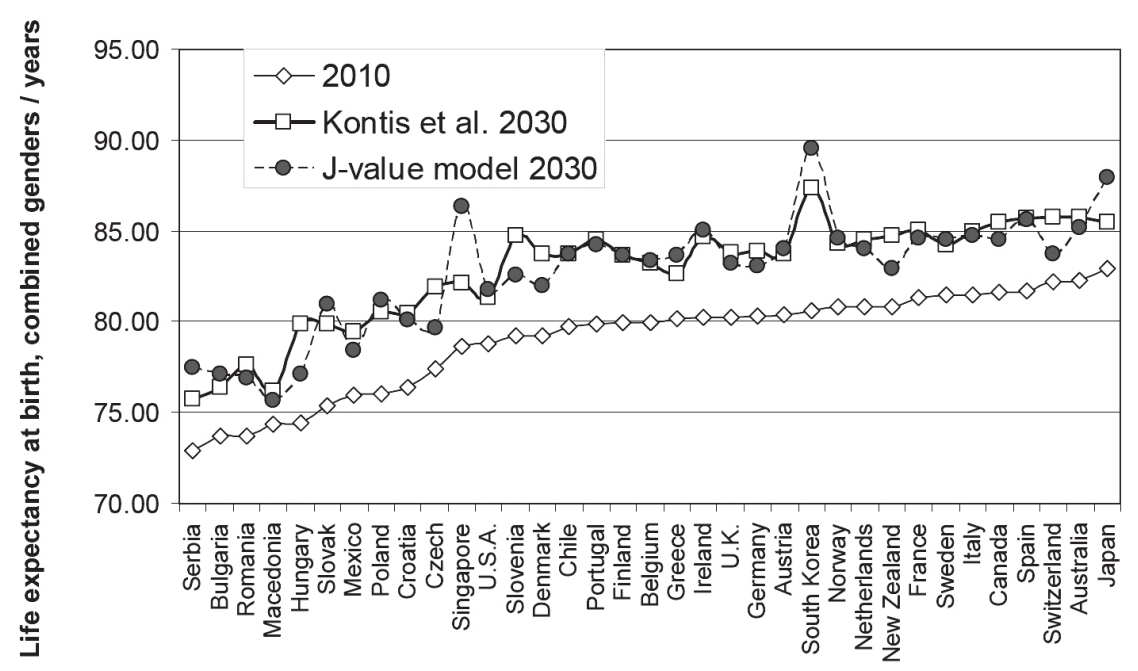

Figure 2. Life expectancy at birth in 2010 and 2030 by country: Kontis forecasts compared with J-value model using long-term, historic growth rates and no male catch-up.

It is possible to find the growth rates for GDP per head needed for the J-value model to match the Kontis prediction exactly for each nation by rearranging equation (13), with the subscript $i$ used to identify the particular nation:

$$
g_{i}=\left(\frac{X_{i}(0)}{X_{\text {Afi }}(0)\left(1-\left(1-r_{X i}(t)\right) f_{\mathrm{m}}\right)}\right)^{\frac{1}{n\left(1-\varepsilon_{\mathrm{p}}\right)}}-1 \quad i=1,2, \ldots, 35
$$

and then inserting the Kontis prediction for $X_{i}(0)$ in 2030. The results have been graphed in Figure 3. This shows the long-term historic average growth rate significantly higher than that needed to provide an exact match to the Kontis figure in the cases of Singapore, South Korea and Japan. These exhibited strong growth in GDP per head in the 1960s through to the 1980s, but growth has slowed more recently. It is quite possible that a more recent figure for growth in GDP per head would be more appropriate for use within the J-value model.

To explore this possibility, a second set of J-value projections was made after applying the average rate of GDP per head growth for each nation for the 20 year period ending 2015 (18 years for Croatia, Serbia and Slovenia). Male catch-up was also incorporated based on the model used to represent the phenomenon in the UK.

3.3 Life expectancy projections for 35 industrialized countries using the J-value model incorporating male catch-up and GDP per capita growth rates 1996 to 2015.

The J-value model incorporating male catch-up (equations 11 and 13) was applied to the female life expectancy at birth, $X_{\mathrm{fA}}(0)$, in 2010 in each of the 35 industrialized countries of the Kontis study.

To find the ratio of male to female life expectancy at birth in 2030, it was assumed that the 2 nd order step response model for predicting $r_{X}(t)$ applicable to the UK (equation 11) applied to all 35 nations. For 33 out of the 35 countries the parameters $T_{\mathrm{n}}, r_{X}\left(t_{0}\right)$ and $r_{X \max }$ were assumed to take the values listed in Table 3 , and the date $t_{0 i}, i=1,2, \ldots, 33$ at which male catch-up starts was 


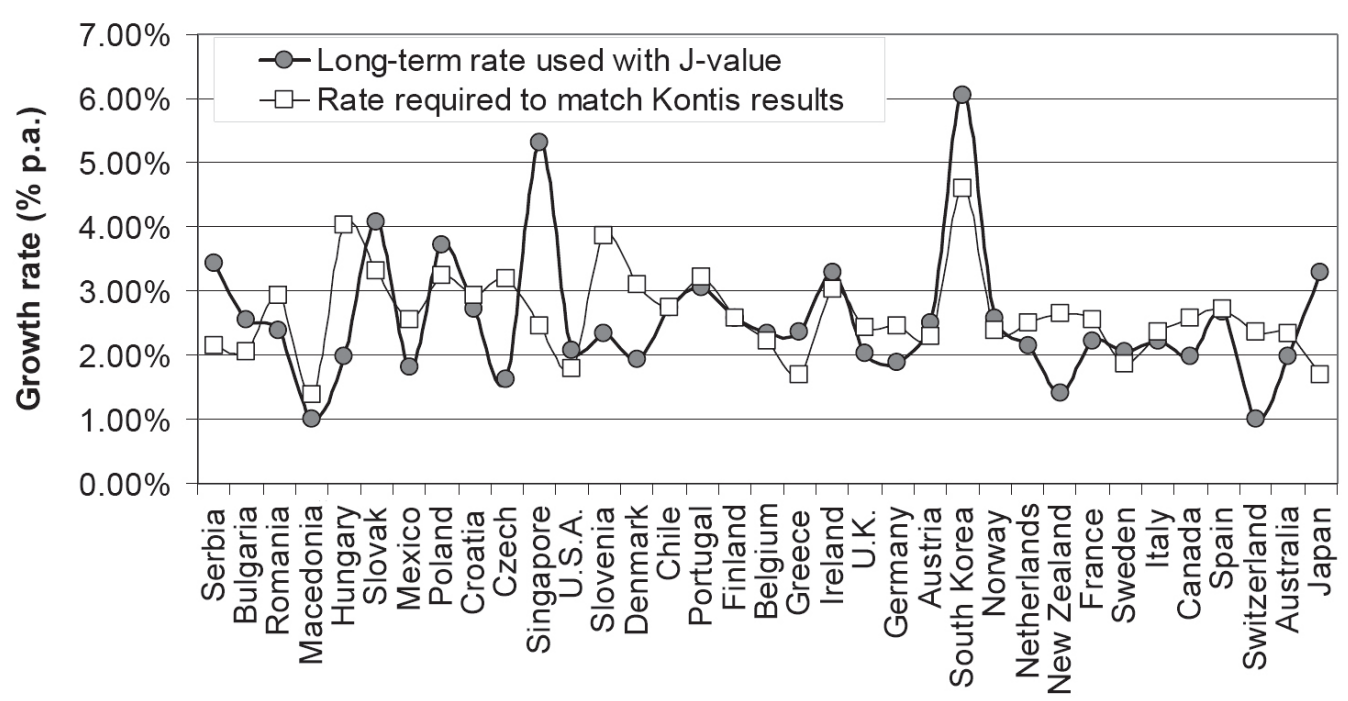

Figure 3. Comparison of GDP per capita growth rates with those needed to match the Kontis predictions for combined gender life expectancy in 2030.

adjusted to match exactly the value of $r_{X i}(2010), i=1,2, \ldots, 33$, for each nation. This procedure needed to be modified in the case of Hungary and South Korea, since the recorded value of $r_{X}(2010)$ lay below the minimum value of the ratio $r_{X}\left(t_{0}\right)=0.9178$ for the UK. In these two cases it was decided to set $t_{0 i}=2010$ and $r_{X i}\left(t_{0 i}\right)=r_{X i}(2010)$, implying that for those two countries the male catch-up process only began in 2010 and from a lower base than for the UK.

The average date of onset of male catch-up across the 35 nations emerged as $\bar{t}_{0}=1977$, which is fairly close to the back-calculated value for the UK, $t_{0}=1973.6$. This lends weight to the proposition that the process of male catch-up has broadly similar characteristics across these industrialized countries and supports the choice of the UK model as a reasonable approximation.

Growth rates for GDP per head, $g_{i}, i=1,2, \ldots, 35$, were considered for the period 1996 to 2015 , with 20 years of data available for 32 nations, but with only 18 years' worth for Croatia, Serbia and Slovenia. The resulting average long-term growth rate of GDP per head across the 35 nations was $2.05 \%$ p.a.

Figure 4 shows a comparison of the J-value calculated life expectancy at birth in 2030 for combined genders with the Kontis et al. results on a country-by-country basis. It is clear that there is good agreement overall between the Bayesian model averaging and J-value models incorporating male catch-up, especially for the top 25 nations as ranked by life expectancy at birth in 2010 (Singapore and the countries to the right of it in Figure 4).

As shown in Table 6, the average life expectancy at birth for combined genders calculated from the J-value model lies within two weeks of the Kontis projections for 2030 for the top 25 countries. By contrast the J-value predicts for the bottom 10 countries a life expectancy at birth for combined genders that is two and a quarter years less than the Bayesian model averaging forecast.

Another perspective on the difference between the bottom 10 of the 35 industrialized nations and the top 25 comes from comparing the 20 year growth rates used with those required to match the Kontis projections. Averages of the required growth rates in GDP per head are compared in Table 7 with the baseline averages used in the J-value model with male catch-up. 


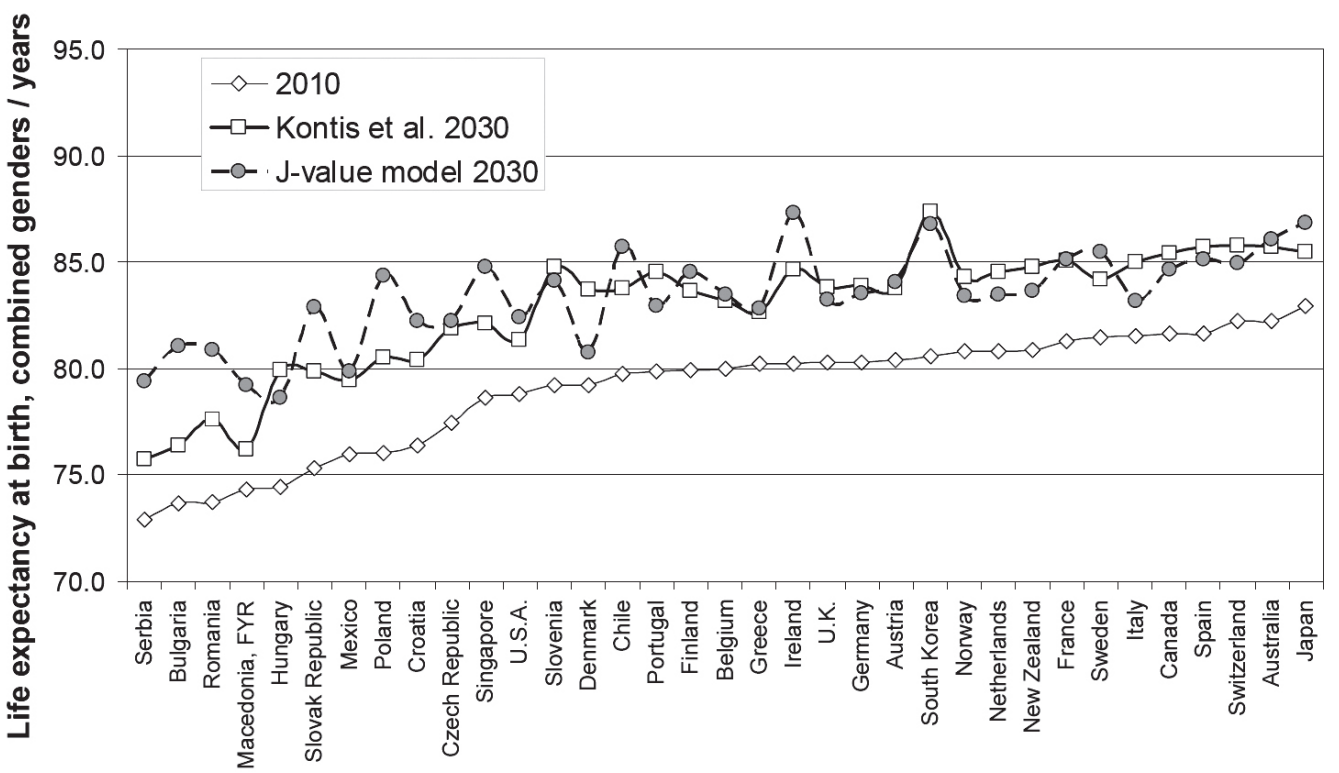

Figure 4. Life expectancy at birth in 2010 and 2030 by country. Kontis forecasts compared with J-value model using average growth in GDP per head over the 20 years to 2015 and incorporating male catch-up.

Table 6. Combined genders life expectancy at birth in 2030: Kontis versus J-value model incorporating male catch-up. Averages for bottom 10 and top 25 nations as ranked by combined genders life expectancy in 2010.

\begin{tabular}{lccc}
\hline & & Kontis & J-value \\
\cline { 2 - 4 } & 2010 & 2030 & 2030 \\
\hline Bottom 10 nations for combined genders life expectancy in 2010 & 75.02 & 78.82 & 81.08 \\
Difference, Kontis - J-value model / years & & & 2.26 \\
Top 25 nations for combined genders life expectancy in 2010 & 80.60 & 84.37 & 84.34 \\
Difference, Kontis - J-value model / years & & & 0.04 \\
\hline
\end{tabular}

The table shows the mean value of GDP per head growth for the top 25 nations needed to match the Kontis projections and the mean value of GDP per head growth for the bottom 10 nations needed for a match. The table suggests that, for the top 25 nations, the Kontis projections for 2030 will be close to the mark provided that the growth rates in the future match the 20 -year average growth rates observed in the past. However, for the Kontis predictions to be valid for the bottom 10 nations, the J-value model suggests that their average GDP per head will need to decrease by an average of $1.61 \%$ p.a. over and above their long-term growth rates.

The relatively poor match between the J-value and the Kontis models for the bottom 10 nations suggests that that the UK description of male catch-up is a much better characterization for the top 25 countries than for the bottom 10. Replacing the life expectancy ratio in 2030 calculated as described at the beginning of this section by the value of $r_{X}(2030)$ implied by the Kontis data (Table 5) for the bottom 10 nations brings the J-value and Kontis predictions much closer, so that the average values for life expectancy at birth for the top 31 countries are now separated by less than a month (see Table 8). However, the J-value predicts a higher 2030 life expectancy at birth for the bottom four countries, Serbia, Bulgaria, Romania and Macedonia, on average 2.2 years longer than suggested by Kontis. 
Table 7. Long-term average GDP per head growth used in J-value forecasts and the average value needed to match Kontis projections for combined genders life expectancy at birth in 2030. Bottom 10 and top 25 nations, as ranked by combined genders life expectancy at birth in 2010 .

\begin{tabular}{lcc}
\hline & Kontis & J-value \\
\hline $\begin{array}{l}\text { Combined genders life expectancy (in years) in 2030, bottom 10 nations } \\
\text { Average long-term growth in GDP per head used in J-value model for } \\
\text { the bottom 10 nations (\% p.a.) }\end{array}$ & 78.82 & 81.08 \\
Average growth in GDP per head needed for a match to Kontis value for & $3.02 \%$ \\
bottom 10 nations (\% p.a.) & & $1.41 \%$ \\
$\begin{array}{l}\text { Combined genders life expectancy (in years) in 2030, top 25 nations } \\
\text { Average long-term growth in GDP per head used in J-value model for } \\
\text { the top 25 nations (\% p.a.) }\end{array}$ & 84.37 & 84.34 \\
$\begin{array}{l}\text { Average growth in GDP per head needed for a match to Kontis value for } \\
\text { top 25 nations (\% p.a.) }\end{array}$ & $1.67 \%$ \\
\hline
\end{tabular}

Table 8. Combined genders life expectancy at birth in 2030: Kontis versus J-value model incorporating male catch-up (matched to Table 5 for bottom 10 nations). Averages for bottom 4 and top 31 nations as ranked by combined genders life expectancy in 2010 .

\begin{tabular}{lccc}
\hline & & Kontis & J-value \\
\cline { 2 - 4 } & 2010 & 2030 & 2030 \\
\hline Bottom 4 nations for combined genders life expectancy in 2010 & 73.66 & 76.50 & 78.70 \\
Difference, Kontis - J-value model / years & & & -2.19 \\
Top 31 nations for combined genders life expectancy in 2010 & 79.70 & 83.59 & 83.66 \\
Difference, Kontis - J-value model / years & & & -0.07 \\
\hline
\end{tabular}

\section{Discussion}

The basic J-value model for forecasting growth in life expectancy derived previously ${ }^{7}$ was based on combined genders data. However, it is clear that in the last 50 years, in industrialized countries at least, there has been a further mechanism at play, namely that male life expectancies at birth have been gradually closing the gap with female. This trend, here designated "male catch-up", is expected to continue and needs to be incorporated into the J-value model so as to provide the most accurate explanation of the growth of life expectancy at birth within an industrialized nation.

A simple model for male catch-up was incorporated without difficulty into the J-value model for predicting life expectancy at birth in the UK. Forecasting from base life expectancies in 1985, the resultant J-value model incorporating male catch-up was found to give a close match to UK life expectancy figures for 2005, using the average growth in GDP per head derived from World Bank figures for the same 20 -year interval. This success adds to the evidence already provided ${ }^{7}$ for the validity of the J-value model for life expectancy growth and, thus, for the J-value in its general role as a criterion for assessing the desirability of safety spending.

Moreover, the J-value model provides a rational explanation for the worldwide growth observed in life expectancy: GDP has been rising across the globe and it is this that is allowing people to live longer. It is suggested that this trend is being picked up in population statistics and provides the underlying reason for the rising levels of future life expectancy predicted by Kontis et al. and others. 
Of course, the fact that the J-value models can provide a close match to the life expectancies at birth forecast by Kontis et al. offers no guarantee that the predictions generated by either method will be confirmed when actual estimates become available in 2030. A more restricted but realistic explanation is that the two methods have used data over similar periods to calculate future life expectancies, with the growth in GDP per head in each country over the period being used directly in the J-value model and indirectly in the Kontis estimates. The latter are projections from population statistics that can be assumed to have been influenced by economic growth in the country concerned.

The extension of life expectancy predicted by the J-value model is assumed to arise from a multiplicity of purposeful decisions on health and safety spending. The intention to increase life quality emerges as one of the major aims in life in all societies. Put simply, we are living longer because we want to do so and are prepared to spend money to make it happen. We will not want to spend all we have, but what we consider prudent. And the richer the society is, as measured by its GDP per head, the greater the resources that can be devoted to enhancing life quality through improving life expectancy. As noted by Kontis et al., ${ }^{10}$ specific social, technological and health system improvements will be very difficult if not impossible to predict, but it is arguable that forecasting the aggregated statistic that is GDP per head should be an easier exercise.

Since life expectancy has not been observed to fall during periods of recession, there is clearly a need for some degree of averaging of the growth rate for GDP per head for use with the J-value method. A typical recession lasts only a short time, perhaps one year or possibly two, and it is credible to assert that a downturn of that length will not make a major difference to health and safety spending while it lasts; such spending is likely to depend on longer-term assumptions about how much is and will be affordable. But it is clearly important to choose a representative value for the average annual growth in GDP per head, as the accuracy of the forecast for life expectancy at birth will obviously be affected by the choice of interval in the past over which to take an average of GDP per head growth as a proxy for the future. It may well be that averaging GDP per head growth rates over the most recent 20 years or so will give a figure more closely aligned with the next 20 years than an average taken over the last 50 years.

The J-value approach has shifted the problem from the extrapolation of past trends in population statistics to the forecasting of economic trends, but we cannot avoid the fact that we are in the prediction game here, with all the uncertainty that such an exercise implies. However, the phenomenological basis of the J-value model focuses our attention towards the rate of growth in GDP per head as the variable having the greatest influence on life expectancy at birth. A particular merit of the J-value model for forecasting life expectancy at birth is the simplicity of the model: just one equation, (3), is needed when no male catch-up is included and only two equations, (11) and (13), when male catch-up forms part of the model.

The model of the ratio of male to female life expectancy at birth (equation 11) was developed to fit UK data on male catch-up and an only slightly modified version was applied to the other 34 industrialized nations. While satisfactory results were obtained for the top 25 industrial nations, there is no doubt that the accuracy of the forecasts for other industrialized countries could be improved by using a version of equation (11) matched more closely to each nation. 


\section{Conclusions}

The J-value model, developed to explain pan-national differences in life expectancy with GDP per head, has been tested in a different role, namely the prediction of future life expectancy at birth within a given country.

The accuracy of the J-value model forecasts can be improved by including a simple allowance for the phenomenon of male catch-up observed over the past 50 years in the UK. The life expectancies at birth calculated by the J-value model incorporating male catch-up compared well with real UK data when projecting over the 20 year interval 1985 to 2005. This success adds to the evidence for the validity of the J-value method.

The J-value model for life expectancy pinpoints growing economic wealth, as measured by GDP per head, as the key driver influencing the health of a nation. A sustained improvement in GDP per head will cause the average life quality in the nation to rise through two mechanisms: (i) annual utility gained from income will be increased; and (ii) the time over which that utility is experienced will be extended, as measured by life expectancy. By the same token, the J-value model suggests that it is inevitable that people will live longer as GDP per head rises. It is clearly desirable for economically successful nations to plan for this phenomenon.

Forecasts for 35 countries made by the J-value model were compared with those produced by applying Bayesian model averaging to 21 projection models that used demographic and not economic data. A close correspondence was found between the results for life expectancy at birth in 2030 calculated by the Kontis approach and those produced by two variants of the J-value model. While the J-value calculations used economic data and the Bayesian model averaging approach employed demographic statistics, it is likely that the GDP data would have had a strong influence on the population data used in the latter technique. This provides an explanation for the good match between the methods, which both based their forward projections on international data collected over a substantial past interval.

Despite its simplicity, the J-value models offer an accuracy in forecasting life expectancy at birth that is comparable to the Bayesian model averaging approach based on 21 separate projection methods. The J-value approach may therefore be recommended to those, such as insurance companies, with an interest in the growth of life expectancy over time. The J-value model for life expectancy is suggested as a complementary method to the models based on demographic projections that are currently in use. 